\title{
Albanian bunkers. Modern fortifications built in socialism
}

\author{
Denada Veizaj $^{\text {a }}$ Gjergji Islami $^{\text {b }}$, Andrea Maliqari ${ }^{\text {c }}$ \\ Universiteti Politeknik i Tiranës, Tirana, Albania, \\ adenada.veizaj@yahoo.com; ${ }^{\text {a }}$ gjergjislami@upt.al; c andrea.maliqari@upt.al
}

\begin{abstract}
During the communist regime of Enver Hoxha, Albania built nearly 200000 bunkers as a measure of protection towards an imaginary attack from (un)known enemies of the Popular Socialist Republic. Most of these structures built in concrete are still part of the landscapes almost in every part of the territory. While the most common type is small and identified from the semi spherical shape, particular bunkers have quite large dimensions and specific features related to their function and location.

During the last five years, three of the most unique modern fortifications built during socialism for the displacement of the governmental authorities in case of war, were revealed and made accessible to the public. These structures, transformed today in museums, cultural spaces or simply visitable attractions, are the symbol of an auto-referenced reality within Europe, where the paranoia produced an unusual typology of modern age fortifications. These bunkers, planned to withstand twentieth century military attacks, are extraordinary structures in terms of engineering and building features, and at the same time they represent a very valuable heritage related to the history of communism in Albania.

This article aims to offer a comprehensive analysis of the fortification of the Albanian territory during the twentieth century as an overall country defence plan, while focusing on the governmental bunkers in order to understand how the ideological differences with the rest of the world created the need for protection and produced an amazing military infrastructure. The discussion on the future of these structures seems to be strongly related to the ability of recognising these modern fortifications on the Mediterranean as cultural heritage.
\end{abstract}

Keywords: Bunker, Albania, socialism.

\section{Introduction - The republic of paranoia}

Albania experienced one of the harshest forms of communist dictatorship during the second half of the twentieth century. In almost five decades, with reference in the Eastern Bloc model, a centralized political and economic system was installed by repressing citizens and by producing one of the most aggressive propagandistic machines of autocratic regimes.

Albania followed a path that led the country towards full isolation in the foreign politics. The enthusiastic relation with the Soviet Union for more than one decade ended with the refusal of the liberal Khrushchev era by the Albanian government. The same political fate will have the relation with China, during the late '70s. Furthermore, apart from inner repression and international isolation, Albania will become in 1967 the first atheist country in the world proclaimed by constitution (Islami, et al., 2018; Payne, 2014).

One of most effective tools used by the government for ideologically controlling the people 
was the fabrication of collective paranoia for unexpected attacks from (un)known enemies. This process was translated in a set of actions in two main domains: in the ideological one by propagandistic means and in the physical features of the territory or of the cities, by adding signs that would imply the terror of a possible attack. The latter resulted in a strategic plan of covering the country's territory with fortifications (Fig. 1); that would serve essentially as defensive structures.

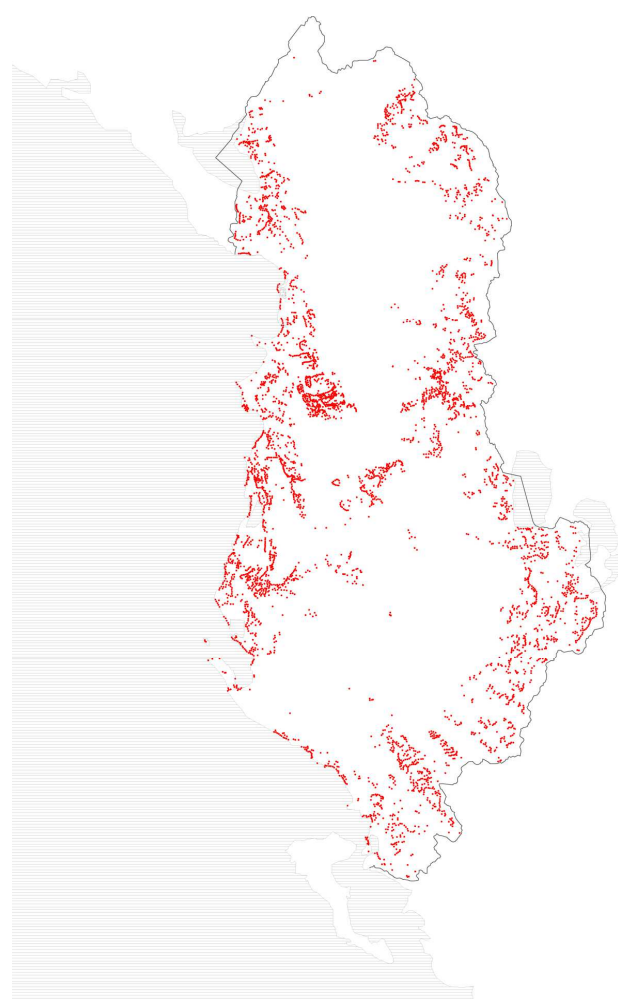

Fig. 1. Distribution of communist fortifications in the territory of Albania till 1983. Bunkers are mainly located along the coastal area, along the borderline with Greece and Yugoslavia, and in the central area near the capital, Tirana (Authors).

Although Albania was isolated in the international arena both from the East and the West, still the fortification project can be seen as a local development related to the Cold War. Because of its uniqueness and of the very contextual nature of the phenomenon, a comparative analysis with the fortification culture of other countries, during the same period, has not been considered appropriate in methodological terms.

The project for the fortification of the defence lines, was an outcome of the 12th Plenum of the Central Committee of the Party of Labour of Albania held in 1971. The goal was to transform the country into an impenetrable castle. On the other hand, the concept of People's Military Art was used for the defensive strategy which presumed that the whole population should have military preparation and should be organized and armed in case of danger (Plenumi i KQ të PPSH, 1971-1978). The intensive fortification project started to be implemented in 1975 and was suspended in the mid 1980s, after Enver Hoxha's death. Until 1983, 173371 bunkers and fortified structures were built, out of the 221143 planned (Bunkart, 2014).
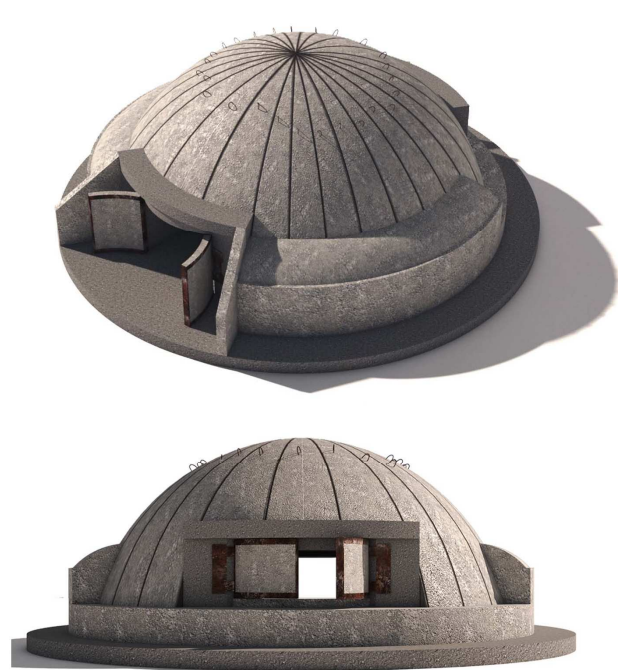

Fig. 2. Reconstruction based on survey documentation. Typical medium size bunker (visualisation Flavio Dervishi \& Uendi Konduri, 2019).

Several data on the bunkers (some of them contradictory) are offered in the information exhibited in Bunkart museum in Tirana and the research project Concrete Mushrooms (Stefa, Mydyti, 2012). Referring to the above, a tentative sorting for the fortification typologies can be as follows: 
- Small Bunkers. Firing Point [Qendër Zarri] for the people, are the smallest and more common bunkers found all over the territory. The small bunkers are found everywhere including urban and non-urban areas, in seashore or mountain, in residential blocks or in strategic locations. The hemispherical shape concrete bunkers are prefabricated and transported into the site. They were intended for soldiers or the common population. 161878 bunkers of this type were built up to 1983 .
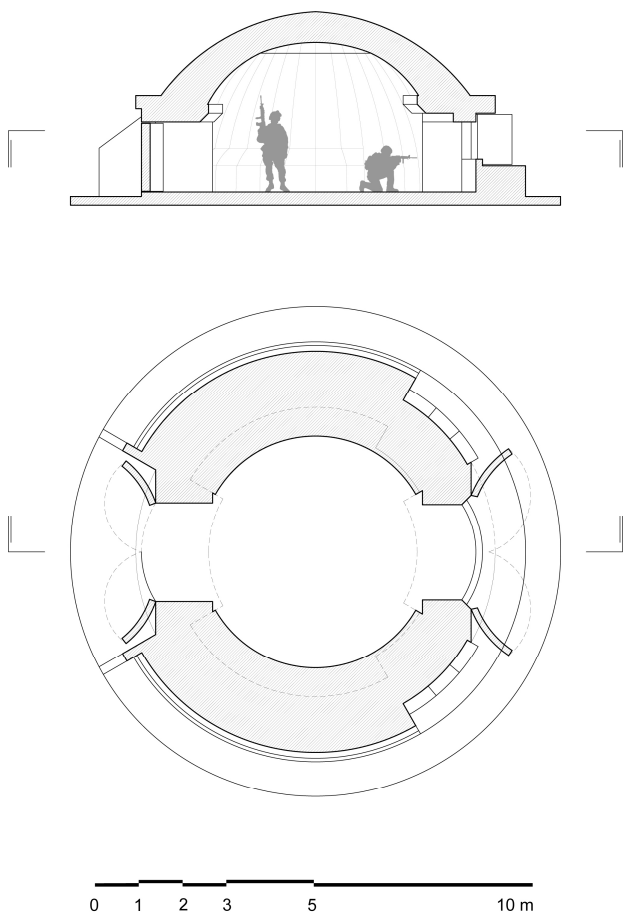

Fig. 3. Plan and section drawings based on survey documentation of a typical medium scale bunker ( $\mathrm{Au}$ thors).

- Medium size Bunkers. Firing Point (Qendër Zarri) against tanks (Figs. 2 and 3). These were larger structures similar to the smaller ones, intended for the use of professional soldiers and heavy artillery. The medium size bunkers are generally located in strategic positions and are rarely found in urban zones. Also these bunkers were prefabricated, but due to their dimensions they were transported in smaller elements and assembled in situ. While the mushroom shape is the most typical, variation on shape and size exist. 9824 bunkers of this type were built up to 1983.

- Large Bunkers. These were special structures built usually for commanding the military operations or depositing weapons and military logistics. These structures are generally tunnel bunkers, located in strategic points relevant to the military tactics. Typically they are built both with prefabricated elements and in situ construction works. 1669 structures of different sizes were built up to 1983 .

Excluding the above, many other non-military defensive constructions exist especially in urban residential areas. They are referred as "shelters" (Vendstrehime), a term related to underground tunnels in urban areas meant to shelter the population during attacks. These structures are meant for civilian protection and not for military action.

As the bunkers were widely spread during the second wold war and especially during the Cold War, Albanian engineers did bring the existing technology for building the structures. Many of them were sent in foreign countries for training and for acquiring the required technology for producing the steel and the special concrete, resistant to bombs or even chemical weapons.

\section{The postsocialist condition}

The focus of the paper is to evaluate the presence of a recent fortification system from the perspective of urban and territorial development. In this regard, it is important to explore two main questions that somehow relate this specific form of modern fortifications and the territory. First, how are these structures related to diverse territorial typologies, starting from non-urban landscapes to city-centres? And second, following the considerable degree of their presence, what will be the future of these fortifications in the post-communist developments?

The free-market economy of the post-socialist system brought very innovative and flabbergasting solutions of transforming these structures, by mostly relying on spontaneous gestures and on the creative potential of individuals, coping with 
and adapting to the new social and economic conditions (Fig. 4). Three decades later, a more accurate strategy is required. A strategy that considers typological features of these structures, their relation to the territory and the economic conditions of a typical post-communist country. In this concern, the debate becomes sensitive in the case of fortifications located in central parts of cities, this because of the recent development dynamics. Albania is being gradually transformed into a touristic destination in the southern part of Europe, and its communist heritage is one of the most attractive assets in terms of touristic offer. In this concern, the future of bunkers installed within the cities somehow is envisaged in a scenario that implies their conservation or their adaptive reuse. At the same time, fortifications represent a piece of the entire archaeology of the Cold War, as long as they were produced under the paranoia of the imaginary Western enemy (Blakemore, 2019).

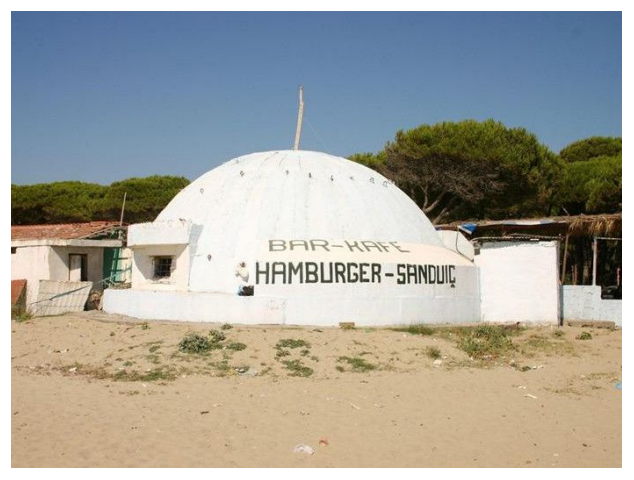

Fig. 4. Transformation of a bunker into a cafeteria (Adnan Asllani, 2005 in Flickr).

The case studies presented in this paper, try to illustrate successful and questionable touristic driven practices of large bunkers reuse by evaluating at the same time the resilience of the structures in functional and spatial terms.

As described in the previous paragraphs, the possible scenarios concerning the future of bunkers would be as follow:

- Reuse for military purposes. Considering the actual political context of the country and also the evolution of military tactics and logistics, this seems to be the least probable scenario, ex- cept in the case of remote areas where bunkers can be used for training activities.

- Adaptive reuse. Changing the bunker's functional programme, in order to integrate them in the new urban contexts of post-socialist Albania has resulted a difficult challenge but at the same time a very attractive business model, especially for tourism.

- Conservation. This scenario is less tourism enthusiast and focuses on recognising, documenting and preserving the bunkers as heritage of the communist period, testimonies of the Cold War and of the fortification culture of the twentieth century in Eastern Europe. Considering that this could be the most valuable trace of modern fortification in the Mediterranean, this culture based scenario seems to be more valuable for the future.

- Demolition. Both economically and ethically, destroying the modern traces of communist fortifications can result unreasonable.

\section{The communist heritage as a touristic po- tential. Fortifications and the risk of ur- banalisation $^{1}$}

The communist past is increasingly becoming a touristic potential, and by consequence the built heritage revealing its reality is nowadays subject of regeneration projects. From the development strategy perspective, the three transformation cases of large bunkers presented in this paper have resulted successful, by creating important touristic spots in the city. Furthermore, transforming these structures in accessible ones, have positively contributed for knowing and documenting them and the nebulous reality they represent.

It is important to mention that bunkers in general appear difficult to demolish, and this fact doesn't contribute in perceiving them as part of a vulnerable heritage stock or as monuments. This lack of sensitivity is revealed through the physical transformations that generally tend to create scenographic environments, rather than thoughtfully preserving and illustrating their history. 


\section{BunkArt}

"Facility 0774", is the huge underground antinuclear shelter, inspired from North Korean models, hosting over 100 rooms in five subterranean levels (Fig. 5). The bunker was built in between 1972-1978, near the Dajti Mountain in the Eastern part of the capital Tirana. It was intended to host the government of the country, by turning the bunker into the headquarters of the defensive command, offering an operational autonomy of approximately one year (Bunkart, 2014; Dowling, 2018). The building, which existence came to light only few years ago, is almost invisible and most of the structure is buried within a hill. Its huge scale demonstrates that the propaganda of terror was produced, but also consumed by the regime itself. Considering the reality of communist Albania, the economic efforts for building the bunker are a testimony of one of the most tragic and comic forms of the Cold War.

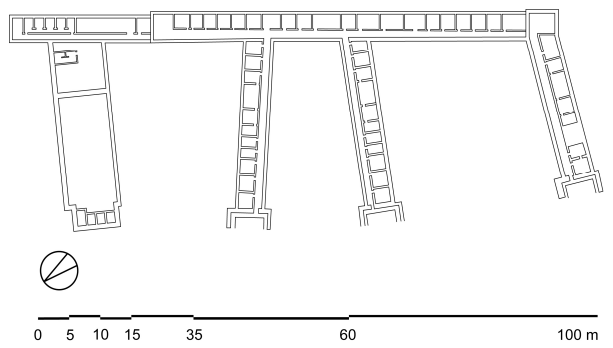

Fig. 5. Plan of the visitable area of Facility 0774 (Authors).

The opening to the public in 2014 resulted in an unprecedented interest where 70000 visitors approached the facility in the first two months (Crevar, 2017).

Despite the tendency of producing a narrative and a series of interpretations over the theme of communism, the experience of the military facility itself still remains readable and perceivable, by constituting a plausible form of reuse of the structure (Fig. 6).

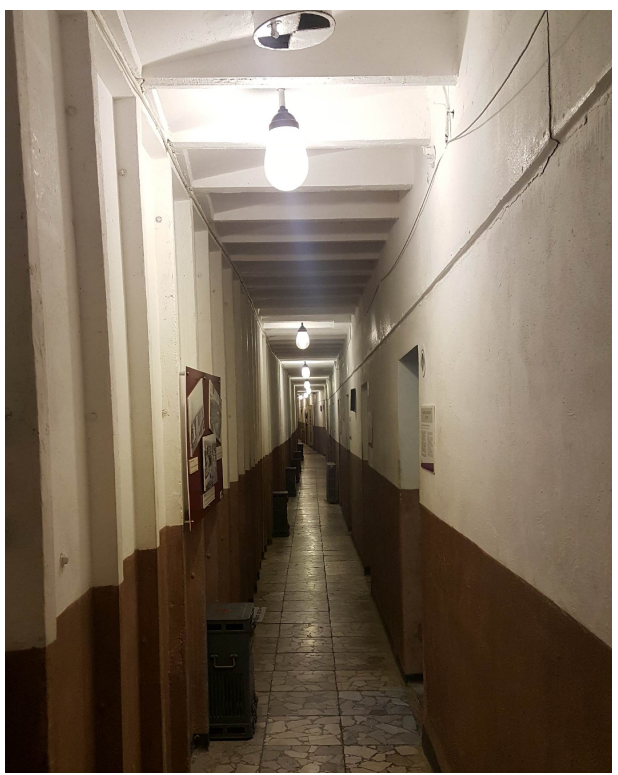

Fig. 6. Typical view of an inner corridor in Bunkart (Authors, 2019).

\section{BunkArt 2}

Following the touristic success of BunkArt, a second similar intervention is proposed in 2016 by transforming an existing underground bunker at the margins of the ex-administrative area of the communist government. "Objekti Shtylla", is the large underground bunker, hosting 24 rooms, built in between 1981-1985 for the Ministry of Internal Affairs (Bunkart 2, 2016) (Fig. 7).

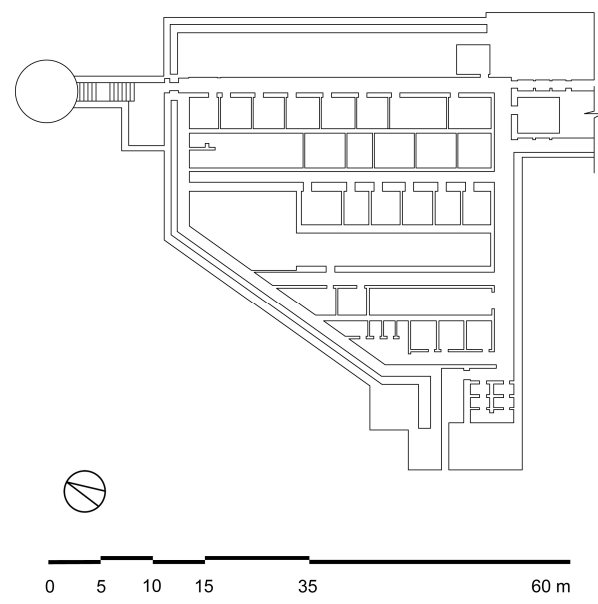

Fig. 7. Plan of Objekti Shtylla (Authors). 
The location within the city is very central, and in this case, the touristic agenda seems to have dominated conceptually and physically the transformation of the bunker (Fig. 8).

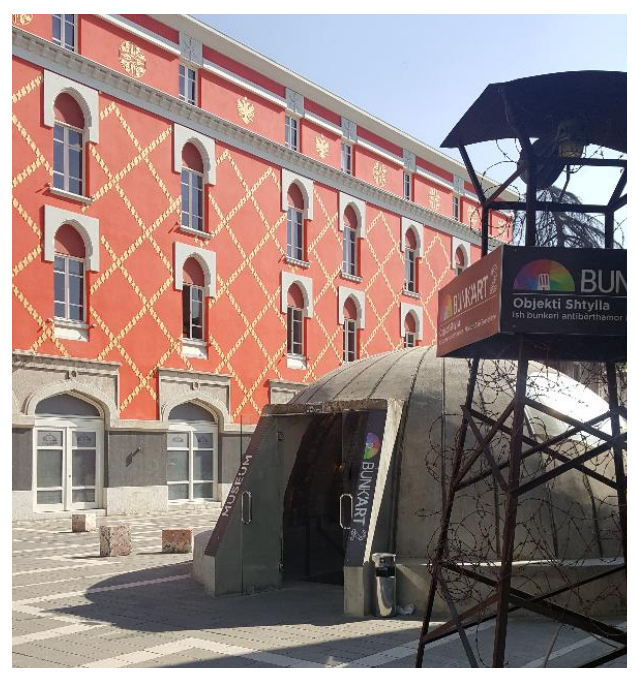

Fig. 8. Fake bunker serving as entrance for Objekti Shtylla. The new entrance has been added to make the bunker easily accessible and visible to tourists (Authors, 2019).

The case illustrates how the added architectural program dominates the value of the building itself. The idea of adapting the structure into a museum focussed on communism somehow detaches the visitor's attention from the real artefact: the bunker. Transforming the place according to an agenda influenced by the globalized concept of tourism has produced an optimal condition for what is nowadays known as "urbanalisation", that means producing repetitive urban circumstances despite the existing local features.

\section{Cold War Tunel in Gjirokastra}

Another interesting case of opening to the public of military fortifications is the Cold War tunnel in Gjirokastra. The city is the hometown of the Albanian communist leader, Enver Hoxha. The existence of the tunnel came to light only after the 1990s. The structure was built during the 1970s, and contains around 50 rooms located in a gallery excavated below the Castle of Gjirokastra in a very central location (Fig. 9).
The whole system is connected via galleries to several administrative buildings in the city.

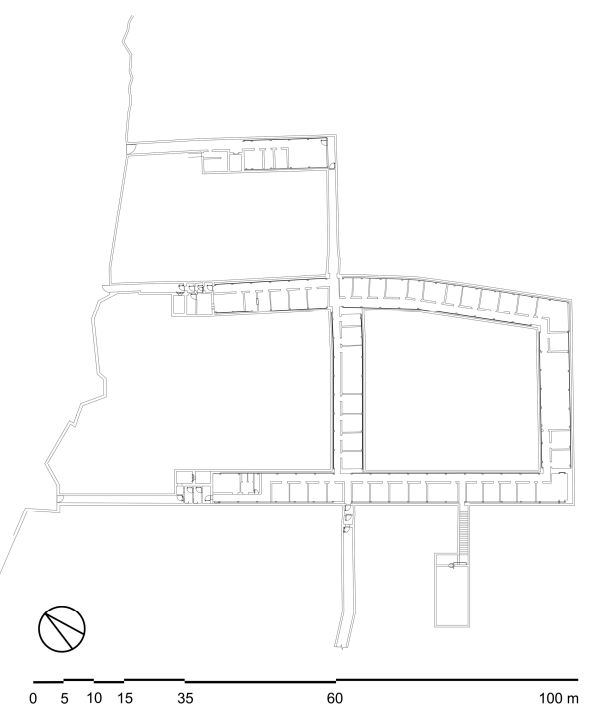

Fig. 9. Plan of the Cold War Tunnel (Authors).

Differently from the previous interventions, in Gjirokastra there are no visible efforts to transform the tunnel in an exhibition area. As a visitor it is possible to experience the real atmosphere of such structures, by fully focusing the attention to the fortification itself.

The bunkers built in Albania during the communist period constitute an immense heritage that still needs to be documented and catalogued. The stock represents an important part of the country's history but also of the Cold War heritage in general. On the other hand, the structures are traces of a different form of fortification built in the Mediterranean area, a product of ideology, politics and technology.

In such a unique context, speaking of conservation and valorisation of the Cold War archaeology, and avoiding the risk of tourist enthusiasm that can led to banalscapes, could be a sustainable policy for dealing with a recent but much valuable past that risks to be lost before fully recognised.

\section{Notes}

${ }^{1}$ According to Francesc M. Muñoz "the process of standardisation and replication of similar ur- 
ban spaces in different cities" is referred as urbanalisation. "This production of common urban landscapes is based on the use of strategies like imitation, selection or the use and manipulation of urban history and historical urban form...
This is a process in which urban design and architecture are the main tools for the production of the common landscapes of urbanalisation: the banalscapes" (Muñoz, 2010).

\section{Bibliography}

Blakemore, E. (2019). Archaeology reveals Cold War nuclear bunkers in Poland, in https://www. nationalgeographic.com (2019).

Bunkart (2014a). Objekti nëntokësor 0774. Vendkomanda e Shtabit të Përgjithshëm, Bunkart, Tirana.

Bunkart (2014b). The fortification of the defense lines, Bunkart, Tirana.

Bunkart (2016). Ish bunkeri antibërthamor i Ministrisë së Brendshme, Bunkart 2, Tirana.

Crevar, A. (2017). Paranoid Dictator Built Thousands of Military Bunkers-See Them Now, in https://www. nationalgeographic.com (2019).

Dowling, S. (2018). Communist Albania was Europe's most isolated nation. Fearing invasion, its regime built a topsecret nuclear bunker. Today that bunker is an eerie tourist attraction, in https://www.bbc.com (2019).

Islami, G.; Veizaj, D.; Thomai, G.; Fontanari, E. (2018). Under pressure - facts of socialist architecture in Albania, Flesh, Tirana.

Muñoz, F.M. (2010). "Urbanalisation: Common Landscapes, Global Places", in The Open Urban Studies Journal, Issue 3, pp. 77-88.

Payne, J. (2014). "Projekti bunkerizimit: The strange case of the Albanian bunker", in Log, Issue 31, pp. 161-168.

Plenumi i KQ të PPSH (1971-1978). "Konkluzione. Nga mbledhja e Plenumit të 12-të të Komitetit Qendror të PPSH «Mbi masat për përsosjen e mëtejshme të përgatitjes e të gatishmërisë luftarake të ushtrisë dhe të forcave vullnetare të vetëmbrojtjes popullore»", in Dokumente kryesore të Partisë së Punës të Shqipërisë, 8 Nëntori, Tirana, pp. 52-67.

Stefa, E.; Mydyti, G. (2012). Concrete mushrooms, dpr-Barcelona, Barcelona. 
